\title{
As modificações de tipologia de unidade de conservação de proteção integral: uma análise do caso "Rangedor” em São Luís (Ma)
}

The typology modifications of a integral protection area: analysis of the "Rangedor" case in São Luís (Ma)

\section{Lorena Saboya Vieira Soares ${ }^{1}$, Rita de Cássia Oliveira Marinho ${ }^{2}$}

RESUMO: Discute-se, no presente trabalho, a mudança de tipologia do Sítio do Rangedor, de Estação Ecológica para Parque Estadual, bem como suas implicações jurídicas. Analisou-se o motivo pelo qual essa unidade de conservação fora criada, quais as características dessa área e o processo de modificação de tipologia. Realizou-se um levantamento sobre as causas da mudança de categoria de unidade de conservação e suas consequências. Por fim, permite-se a reflexão sobre a implementação do Parque Estadual do Rangedor.

PALAVRAS-CHAVE: Direito Ambiental; Unidades de Conservação; Parque Estadual do Rangedor.

ABSTRACT: This present work discuss the typology modification of the Rangedor Site as a Ecological Station to State Park, as well as its legal implications. It was analyzed the reason of the conservation unit was created, the characteristics of the area and the process of typology modification. It was realized a survey about the causes of the change of conservation unit category and its consequences. Finally, provides a reflection about the implementation of the Rangedor State Park.

KEYWORDS: Environmental Law; Conservation units; State Park of the Rangedor.

\footnotetext{
${ }^{1}$ Advogada. Graduada em Direito pela Universidade Ceuma (2003). Pós-graduada em Direito Ambiental (Atame Brasília/DF). Mestre em Saúde e Ambiente pela Ufma (2009). Atualmente, é doutoranda em Políticas Públicas pela UFMA, vice-presidente do Instituto Maranhão Sustentável, professora da graduação e pós-graduação da Universidade Ceuma. E-mail: lorenasaboia@gmail.com

${ }^{2}$ Advogada. Egressa do curso de Direito da Universidade Ceuma (2017). E-mail: rita.cassia0241@gmail.com
} 


\section{INTRODUÇÃO}

Atualmente, a expressão "proteção ambiental” tornou-se muito popular em todo o mundo, já que se tem o entendimento de que a vida humana, a animal e a vegetal estão totalmente dependentes do meio ambiente. Por isso, houve a preocupação em implementar-se práticas sustentáveis na tentativa de conciliar o desenvolvimento econômico ao social, ao ambiental e ao cultural.

No Brasil, os marcos regulatórios ambientais foram de suma importância nesse processo de busca pela sustentabilidade. Pode-se citar, como um dos principais diplomas, nesse contexto, a própria Constituição Federal de 1988, que reconheceu o meio ambiente como Direito Fundamental e o estendeu para todas as espécies.

No que se refere à manutenção e à preservação da biodiversidade, a Carta Magna previu diversas obrigações ao poder público, e, em especial, destaca-se a definida no inciso II, do parágrafo primeiro, do artigo 225, que é a implementação de espaços territorialmente protegidos, os quais foram, posteriormente, regulamentados, através da Lei $\mathrm{n}^{\circ}$ 9.985/2000, passando a denominarse Unidades de Conservação.

A Lei 9.985/2000 definiu diversos tipos de Unidades de Conservação e os dividiu em dois grandes grupos: de proteção integral e de uso sustentável, a depender da necessidade maior ou menor de proteção, bem como da possibilidade de interação humana com o meio. Assim, ao criar a Unidade de Conservação, há a necessidade da indicação, por ato legal do poder público, do "grupo" e do "tipo", diferenciando-se, assim, as regras de gestão e uso do referido espaço.

O texto legal permitiu a modificação tanto de tipologia quanto de grupo de Unidades de Conservação, porém deve-se obedecer a critérios para tanto.

Recentemente, no estado do Maranhão, houve a alteração do tipo de Unidade de Conservação, de Estação Ecológica do Rangedor para Parque Estadual do Rangedor.

Assim, o presente estudo tem como objetivo demonstrar as implicações jurídicas da citada modificação de tipologia, especialmente pela relevância ambiental, que esta área possui para a cidade de São Luís, e o contexto jurídico que envolveu a alteração do "Rangedor". 


\section{CONSIDERAÇÕES SOBRE A PROTEÇÃO DO RANGEDOR AO LONGO DO TEMPO}

Segundo o que estabelece a Lei 9.985/200 (artigo $2^{\circ}$, I), considera-se Unidade de Conservação o espaço territorial e seus recursos ambientais, que incluem as águas jurisdicionais, com características naturais relevantes, legalmente instituídos pelo Poder Público, com objetivos de conservação e limites definidos, sob regime especial de administração, ao qual se aplicam garantias adequadas de proteção.

Por proteção integral, estabelece o mesmo artigo da Lei que é a manutenção dos ecossistemas livres de alterações, causada por interferência humana, ao admitir apenas o uso indireto dos seus atributos naturais.

Segundo Figueiredo (2013, p. 316), uma Unidade de Conservação, do tipo Proteção Integral, tem "o objetivo básico de preservar a natureza, pois é admitido apenas o uso indireto dos seus recursos naturais".

Criada através do Decreto Estadual no 21.79715 de dezembro de 2005, a antiga Estação Ecológica do Rangedor fica localizada nas imediações dos bairros do Calhau, Renascença, Santa Eulália, Vinhais I, Quitandinha e Cohafuma, no município de São Luís/MA, e tem por objetivo principal possibilitar o equilíbrio ecológico e a preservação da fauna e da flora locais.

De acordo com o Decreto instituidor, os objetivos específicos do Rangedor são: manter as propriedades geotécnicas, pedológicas e fisiográficas locais; ajudar no processo de infiltração de águas pluviais; proporcionar a sua preservação por ser uma área de recarga de aquíferos de interação com a dinâmica das águas da microbacia do rio Calhau e com a sub-bacia do rio Anil; preservar amostras da flora e da fauna locais; e permitir, futuramente, que sejam realizados estudos comparativos com as áreas, da mesma região, ocupadas e modificadas por ações antrópicas.

O estudo realizado na área, para subsídio da criação da Unidade de Conservação, apontou a importância do local para a sustentação ambiental no que se refere aos impactos das águas pluviais nas reservas de água subterrânea (LORÊDO; FILHO, 2013), e, por isso, sugeriu-se o tipo Estação Ecológica, do Grupo de Proteção Integral.

De acordo com Lorêdo e Filho (2013), a possibilidade do Rangedor ser criado na categoria de Parque Estadual foi descartada pelos pesquisadores, que elaboraram o estudo-base para a constituição da Unidade, por se tratar de uma área com pequenas extensões. 
Segundo o artigo $9^{\circ}$ da Lei $n^{\circ}$ 9.985/2000, as Estações Ecológicas são unidades de conservação que têm como principal finalidade a preservação da natureza, bem como a execução de pesquisas científicas (BRASIL, 2000).

O Rangedor está localizado, totalmente, em área urbana, envolto por três avenidas de grande movimentação (Jerônimo de Albuquerque, Holandeses e Eduardo Magalhães), e possui uma área inicial de 125,65ha (cento e vinte e cinco hectares e sessenta e cinco ares).

A administração do Rangedor é de responsabilidade da Secretaria de Estado de Meio Ambiente e Recursos Naturais do Maranhão - Sema, a qual, segundo o artigo $4^{\circ}$ do Decreto $\mathrm{n}^{\circ}$ 21.797/2005, deve realizar sua gestão e manutenção.

Em sete de agosto de 2007, o Decreto $n^{\circ} 23.303$ redefiniu a área do Sítio Rangedor, que passou a compreender uma área de 120,95ha (cento e vinte hectares e noventa e cinco metros quadrados), com um perímetro de 5.569,90m (cinco mil, quinhentos e sessenta e nove metros e noventa centímetros), e, posteriormente, houve a construção do prédio da Assembleia Legislativa do Estado do Maranhão em seu entorno.

A justificativa para a redução da área do Rangedor, constante no sítio eletrônico da Assembleia Legislativa do Maranhão ${ }^{3}$, é a de que, antes da criação dessa Unidade de Conservação, a área já estava comprometida para a construção do prédio da Assembleia Legislativa, que tem um perímetro de 1.242,48m (um mil, duzentos e quarenta e dois metros) e área de 8.498,5ha (oito mil, quatrocentos e noventa e oito hectares e cinco ares).

Segundo Lorêdo e Filho (2013), a primeira parte do terreno, para construção da nova sede da Assembleia Legislativa do Maranhão, foi doada pelo Governo do Estado, através da Lei ${ }^{\circ}$ 7.373/99, com uma área de $46.350 \mathrm{~m}^{2}$ (quarenta e seis mil e trezentos e cinquenta metros quadrados); e, em 2003, a segunda parte, que compreende uma área de $38.634,84 \mathrm{~m}^{2}$ (trinta e oito mil e seiscentos e trinta e quatro metros quadrados), através da Lei 7.997/03.

Durante o período de existência da Estação Ecológica do Rangedor, desde a sua criação, diversos foram os desafios enfrentados para a preservação da área, diante das externalidades locais, como: invasões, corte de árvores e queimadas, que ocasionavam a perda de biodiversidade e a morte de animais.

Alguns programas foram executados com o intuito de reparar tais danos ou evitá-los, como: atividades educativas e plantio de mudas de espécies nativas, embora, muitas vezes, esses

\footnotetext{
${ }^{3}$ Disponível em: 〈http://www.al.ma.leg.br/noticias/20627〉. Acesso em: 02 out. 2017.
} 
projetos acabassem prejudicados, especialmente, na época seca (segundo semestre) pela maior incidência de queimadas no local.

O Plano de Manejo ${ }^{4}$ do Rangedor ainda não havia sito instituído, o que dificultou, também, o desenvolvimento de ações de manutenção da Unidade, bem como a delimitação dos acessos permitidos.

O Rangedor, conforme será demonstrado a seguir, hoje, é um Parque Estadual com Plano de Manejo devidamente estabelecido.

\section{O PROCESSO DE MODIFICAÇÃO DE TIPOLOGIA DO RANGEDOR DE ESTAÇÃO ECOLÓGICA PARA PARQUE ESTADUAL}

No dia 11 de maio de 2016, a sessão do Plenário da Assembleia Legislativa do Estado do Maranhão aprovou o Projeto de Lei $n^{\circ} 321 / 2015$, que, posteriormente, resultou na Lei Estadual $\mathrm{n}^{\mathrm{o}} 10.455 / 2016$, alterando a categoria da unidade de conservação da Estação Ecológica do Sítio do Rangedor para Parque Estadual do Sítio do Rangedor, ainda dentro da categoria de unidade de proteção integral, definida pela Lei Federal n ${ }^{\circ}$ 9.985/2000.

O Parque Estadual, de acordo com o artigo 13 da Lei Estadual n 9413/2011, que instituiu o Sistema Estadual de Unidades de Conservação da Natureza - Seuc, é a área de preservação de ecossistemas naturais de relevância ecológica e beleza natural, possibilitando a realização de pesquisas e o desenvolvimento de atividades voltadas para a educação.

Assim, a principal diferença entre uma Estação Ecológica e um Parque é a de que o Parque está voltado às atividades de educação ambiental e recreação em contato com a natureza, bem como ao turismo ecológico; já a Estação Ecológica tem como objetivo o desenvolvimento de atividade educativa (sem visitação pública) e científica, devidamente autorizada e prevista em seu plano de manejo.

A justificativa, presente na lei, para a mudança de tipologia do Rangedor, de Estação Ecológica para Parque, é fundamentada nas queimadas criminosas e não criminosas, no despejo irregular de resíduos sólidos e na prática ilegal de caça que ocorriam no local.

\footnotetext{
${ }^{4}$ Principal instrumento de gerenciamento de uma unidade de conservação, pois é através dele que os objetivos gerais, peculiaridades, o diagnóstico socioambiental da área são traçados, bem como o seu zoneamento ambiental, as normas que devem administrar o uso da área (AMADO, 2015).
} 
Assim, identificou-se que a melhor forma de preservar o objetivo, para o qual o "Rangedor" fora criado, seria a modificação de sua tipologia para Parque.

De acordo com o SNUC (artigo $22 \S 2^{\circ}$ da Lei $n^{\circ}$ 9.985/2000), a instituição de uma Unidade de Conservação, na categoria de parque estadual, só pode ocorrer mediante consulta pública, sendo um critério indispensável no processo de criação.

A consulta pública deve ocorrer, preferencialmente, nos locais diretamente afetados, com ampla divulgação, cujo intuito é colher da coletividade suas opiniões, dúvidas, e, acima de tudo, a vontade popular, por isso a denominação consulta.

Ademais, para a criação de um Parque Estadual é indispensável a elaboração de um plano de manejo, que descreva as especificidades dessa categoria. No caso na área do Rangedor, em junho de 2017, houve a entrega do Plano de Manejo do Parque Estadual do Sítio do Rangedor.

No início de outubro de 2017, o Governo do Estado do Maranhão anunciou ${ }^{5}$ que o Parque Estadual do Sítio do Rangedor sofreria intervenções para a construção de um complexo de lazer. O projeto está orçado, segundo as informações fornecidas pelo governo estadual, em aproximadamente R 19 milhões (dezenove milhões de reais).

De acordo com o projeto, o Parque terá três praças grandes e quatro intermediárias, dois estacionamentos, pista de caminhada, ciclovia, trilhas naturais, academias ao ar livre, quadras poliesportivas, espaços de convivência e uma lagoa, com três portões de acesso, sendo dois destes destinados para a manutenção e uma entrada principal, que ficará aberta ao público, localizada na avenida Luís Eduardo Magalhães.

Dessa maneira, é importante refletir sobre os benefícios que serão alcançados com a mudança de tipologia de uma Unidade de Conservação, especialmente no que se refere à preservação da biodiversidade, sem deixar de levar em consideração a necessidade de interação humana com o meio.

\section{CONSIDERAÇÕES FINAIS}

A criação das Unidades de Conservação tem como objetivo a promoção da preservação da biodiversidade. Assim, necessário se faz que este seja levado em consideração tanto no ato de criação de uma UC quanto na mudança de tipologia.

\footnotetext{
${ }^{5}$ Disponível:<http://www.ma.gov.br/agenciadenoticias/desenvolvimento/meio-ambiente/construcao-do-parque-estadualsitio-do-rangedor-comeca-nesta-semana>. Acesso em: 02 out. 2017.
} 
Sabe-se que os grandes centro urbanos, como o de São Luís, são desprovidos de locais adequados ao lazer, e, muitas áreas, que poderiam tornar-se espaços protegidos, servem hoje de depósitos de resíduos ou de palco para a violência.

No caso do Rangedor, diante de sua importância ambiental, é de grande importância a criação e o desenvolvimento de políticas públicas de preservação, como o combate a incêndios e outros danos que ocorrem no local.

Necessário se faz verificar se a modificação de tipologia do Rangedor, de Estação Ecológica para Parque, propiciará ganhos ambientais e sociais, visto que qualquer intervenção, não adequada ao local, poderá comprometer, inclusive, o equilíbrio ecológico da cidade.

O que se espera é que as medidas, que estão sendo adotadas, sejam eficazes e resultem na preservação e na manutenção do Rangedor, cumprindo-se, assim, o estabelecido no parágrafo primeiro, inciso II, do artigo 225 da Constituição Federal.

\section{REFERÊNCIAS}

AMADO, Frederico. Legislação Comentada para Concursos Ambiental. 1 $1^{\text {a }}$ ed. São Paulo: Método, 2015.

BRASIL. "Constituição Federal de 1988." In: Vade Mecum Saraiva OAB e Concursos, por Editora Saraiva com a colaboração de Lívia Céspedes e Fabiana Dias da Rocha. 12a .ed. São Paulo: Saraiva, 2017.

BRASIL. Decreto $\mathrm{n}^{\circ} 4.340$ de 22 de agosto de 2002. Dispõe sobre a regulamentação dos artigos da Lei no 9.985, de 18 de julho de 2000, que dispõe sobre o Sistema Nacional de Unidades de Conservação da Natureza. Disponível em: http://www.planalto.gov.br/ccivil_03/decreto/2002/d4340.htm>. Acesso em: 08 nov. 2017.

FIGUEIREDO,Guilherme José Purvin de. Curso de Direito Ambiental .6 ${ }^{\mathrm{a}}$.ed.São Paulo: RT, 2013.

LORÊDO, Bruno Costa e DOMINICES FILHO, Célio Rodrigues. Unidades de Conservação, Instrumentos de Conservação da Biodiversidade: Estação Ecológica do Rangedor. 2013. Disponível em: <http://www.webartigos.com/storage/app/uploads/public/588/4cd/e55/5884cde554acf453018599.pd f >. Acesso em: 07 out. 2017.

MARANHÃO. Decreto $n^{\circ} 21.797$ de 15 de dezembro de 2005. Dispõe sobre a Criação da Estação Ecológica do Sítio Rangedor, com limites que especifica. Disponível em: $<$ https://www.jusbrasil.com.br/diarios/6496931/pg-6-executivo-diario-oficial-do-estado-domaranhao-doema-de-15-12-2005>. Acesso em 08 nov. 2017. 